\title{
Politieke geletterdheid in 'n demokratiese Suid-Afrika
}

T. Möller en J.C. Joubert

Departement Psigo- \& Sosiopedagogiek

Universiteit van Pretoria

PRETORIA

\begin{abstract}
Political literacy in a democratic South Africa

In a democracy every enfranchised citizen has an equal say in government, differences are resolved through debate and persuasion and the citizen must have the knowledge to participate in government and to debate differences. When a child is educated in political literacy, a positive contribution to democracy is possible. Compulsory political literacy programmes in schools can prepare the broad masses in South Africa for participation in a democratically elected government.
\end{abstract}

\section{Inleidende probleemstelling}

Die Suid-Afrikaanse burger moes die afgelope twee jaar twee keer na die stembus gaan. Met die verkiesing in April 1994 het ongeveer agtien miljoen kiesers aan die eerste demokratiese verkiesing deelgeneem. Miljoene stemgeregtigdes wat vir die eerste keer kon stem, was egter oningelig en nie geskool in die Westerse demokratiese tradisies nie (Beyers, 1994:57). In November 1995 het die kieser vir die tweede keer gaan stem - dié keer vir plaaslike regerings wat demokrasie op grondvlak gevestig het.

By laasgenoemde stemgeleentheid is voorafregistrasie vereis wat onrusbarend traag verloop het (The Pretoria News, 1995-08-18, p. 3). Redes wat vir die trae registrasie aangevoer was, was onkunde en gebrek aan motivering by die kiesers (SAUK TV 1 Nuus, 15 Augustus 1995). Hieruit blyk dit dat daar 'n moontlike verband bestaan tussen kennis aangaande politieke aangeleenthede en deelname aan 'n demokraties verkose regering. Die vraag kan dus gestel word in hoe 'n mate aandag geskenk word aan politieke geletterdheid as 'n eietydse opvoedingsaangeleentheid in Suid-Afrika. Aspekte wat vervolgens aangaande politieke geletterdheid ondersoek word, is die betekenis van die begrip, 'n prinsipiële begronding daarvan, enkele kontemporêre beskouinge en die verband tussen politieke geletterdheid en demokrasie. Die artikel word afgesluit met 'n aantal gefundeerde aanbevelings en 'n gevolgtrekking aangaande die plek van politieke geletterdheidsprogramme in Suid-Afrika. 
Politieke geletterdheid in 'n demokratiese Suid-Afrika

\section{Wat is politieke geletterdheid?}

Verskillende omskrywings van politieke geletterdheid kan gegee word:

* Die woord politiek is afgelei van die Griekse woord politiké wat verwys na daaglikse lewenservaringe. Dit verwys ook na die woord polis of stadstaat wat 'n geografiese eenheid was en waar daar ordelike bestaan en veiligheid geheers het (Bornman, 1991:8). Aristoteles (vgl. Aristotle, 1966:513) het politiek as ' $n$ weg of middel beskou om die goeie lewe te verseker. Hy noem politiek die "master science" wat alle kennis insluit (Spiro, 1970:2).

* Kotzé en Van Wyk (1980:141) definieer politiek as die idees, instellings en aktiwiteite wat aanleiding gee tot en/of deel vorm van gebeure waarin reels op 'n gesagvolle wyse vir 'n bepaalde samelewing neergelê en afgedwing word.

* Landman (1993:5-6) beskryf politieke wetenskap as 'n begeleidingswetenskap rondom die mens se polities in-die-wêreld-wees.

* Spiro (1970:4) beskryf die begrip politiek as die belangrikste menslike aktiwiteit wat die lewe van individue en gemeenskappe organiseer en beheer.

* Krieger (1993:712) beskou politiek as politieke kultuur en bedoel daarmee: “... subjective attitudes and sentiments as well as objective symbols and creeds that together govern political behaviour and give structure and order to the political process". In die lig van bogenoemde beskrywings kan afgelei word dat politiek 'n eg menslike aktiwiteit is wat gerig is op die organisering, handhawing en bevordering van alle samelewingsverbande. Dit dui dus op ' $n$ reg- en ordeskeppende karakter. (Hoe dit in die praktyk geskied, sal afhang van die ingeligtheid van die deelnemers.)

* Ingeligtheid veronderstel geletterdheid (kundigheid) wat onder andere deur onderrig verwerf $k a n$ word (Odendal, 1994:253).

\section{Prinsipiële begronding}

Alle beskouings oor opvoeding as praktiese aangeleentheid vertrek vanuit ' $n$ besondere prinsipièle beskouing. In hierdie beredenering oor die begeleiding tot politieke geletterdheid binne 'n demokratiese samelewing word aanvaar dat die mens deur God geskape en beelddraer van God is en 'n besondere skeppingsopdrag het, naamlik om oor die skepping te heers. Opvoeding as begeleiding tot die uitvoering van die skeppingsopdrag is sinvol omdat God daaraan sin gee. Opvoeding is gerig op die hele skepping wat God gemaak het.

Na die mens kan dus verwys word as besondere ontisiteit toegerus met latente vermoëns wat deur opvoeding ontwikkel moet word. Die mens is vanaf geboorte 
'n kultuurwese met 'n besondere skeppingsopdrag wat insluit die bewerking, versorging en ontwikkeling van die mens en sy omringende lewenswerklikheid (De Klerk et al., 1973:28).

Kultuur word geopenbaar in 'n aantal komponente waaronder opvoeding ' $n$ belangrike plek inneem. Deur opvoeding moet die kind in die breë kultuurverband bewus gemaak word van wie hy is, wat sy taak is en waarheen hy op pad is (Pretorius, 1985:74). Die sinvraag kan dus alleenlik beantwoord word vanuit die spesifiek lewensbeskoulike. Dit impliseer dat die kultuur en lewensbeskouing van 'n bepaalde groep mense 'n bepalende invloed uitoefen op politieke geletterdheid as opvoedingsaangeleentheid. Waar dit by 'n wêreldbeskouing gaan om die sin en betekenis van die ganse werklikheid wat die mens omring, gaan dit by 'n lewensbeskouing oor vrae rondom die mens self en die sinvolheid van die lewe (Du Plooy et al., 1985:332). Begeleiding tot politieke geletterdheid kan dus nie losgedink word van universele lewenswaardes en spesifieke opvattings aangaande die lewe nie.

\section{Enkele kontemporêre beskouings oor politieke geletterdheid}

'n Kontemporêre beskouing oor politieke geletterdheid is dat dit rasionele kundigheid oor die politiek impliseer en dat dit as 'n breë staatsburgerlike vorming beskou kan word (Trümpelmann, 1985:15-17).

Farnen (1990:340) beskou die uiteindelike doel van politieke geletterdheid as die weg waardeur die mens 'n greep op openbare probleme verkry, die inisiëring van moontlike oplossings vir die probleme, asook die weg waarlangs uitdagings en vraagstukke van die jaar 2001 ontmoet kan word. Deur politieke geletterdheid kan kennis van die demokratiese bestel, besluitnemingsprosesse en vaardighede om daaraan deel te neem, verkry word.

'n Gemeenskaplike uitgangspunt oor politieke geletterdheid soos verwoord deur talle skrywers, byvoorbeeld Brownhill en Smart (1989:31) asook Boyer (1988:288) is die idee van die ideale burger. Brennan (1981:54) vat dit saam in sy beskouing van 'n polities-geletterde burger as iemand wat beskik oor “... a compound of knowledge, skills and attitudes appropriate to political awareness and understanding which are to be developed together and on a practical understanding of concepts drawn from everyday life and language".

Eienskappe van 'n polities-geletterde burger impliseer die volgende in die praktyk:

- 'n Bewus wees van sy burgerlike regte, pligte en moontlike wyses waardeur hy betrokke kan wees in die politiek.

- Kennis van die vervlegtheid van nasionale en internasionale politiek. 
- Kritiese kennis van die eie en ander relevante staatsfilosofieë en regeringstelsels.

- Verdraagsaamheid, redelikheid en vatbaarheid vir ander se politieke oortuigings mits die standpunte nie die demokrasie as sodanig aantas nie en die standpunte op redelikheid gebaseer is.

- Erkenning van die eenheid en verskeidenheid van sy land en die verrekening daarvan in sy standpunte.

- Die onderskryf van waardes soos regverdigheid, gelykheid voor die wet en die gelykwaardigheid van alle mense.

- Aanvaarding dat enige verandering slegs sal slaag as orde en stabiliteit heers (Trümpelmann, 1985:30; Lister, 1976:5).

Vrae wat op grond van bogenoemde eienskappe van 'n polities-geletterde burger ontstaan, sluit die volgende in:

- Wat is die verband tussen politieke geletterdheid en demokrasie?

- Wat word vandag in die skool gedoen ten opsigte van politieke geletterdheid en die opvoeding van die ideale burger?

- Watter bydrae kan die skool en ander instansies lewer om politieke geletterdheid in Suid-Afrika te bevorder?

\section{Politieke geletterdheid en demokrasie}

Die woord demokrasie is afgelei van die Grieks demos wat letterlik "power of the people" (Aristotle, 1966:191-192, 201) en kratos wat krag (regeer) beteken (Odendal, 1994:135; Krieger, 1993:220). Demokrasie verwys daarom na 'n regeringsvorm, waar die mense of volk regeer - in teenstelling met monargieë en aristokrasieë. Demokrasie is 'n begrip wat sedert die klassieke Grieke 'n basisterm in die politieke woordeskat van die mens geword het (Esterhuyse, 1994:2).

In sy eenvoudigste vorm beteken demokrasie 'n regering waarin al die volwasse lede van die samelewing besluitneming kan kontroleer (Odendal, 1994:884). Volgens Odendal (1994:135) beteken demokrasie verder 'n "regeringsvorm deur verteenwoordigers uit die hele volk gekies, gekenmerk deur vryheid van spraak, van die individu, van die reg: volksregering".

De Vries (Beeld, 1995-07-05, p. 6) meen egter dat die oorspronklike beskouing van die demokrasie, naamlik as bloot 'n regeringsvorm deur die inwoners, verander het tot 'n lewenshouding wat gestalte gee aan individuele vryheid en morele verantwoordelikheid, as die grondbeginsels van die demokrasie. 
'n Moderne beskouing van die begrip demokrasie is om dit as 'n prosedure te beskryf in terme waarvan regerings daargestel word, politieke beleidmakings- en besluitnemingsprosesse verloop, die regeerproses plaasvind, regeerders en verteenwoordigers aanspreeklik gehou word en van 'n regering ontslae geraak kan word (Esterhuyse, 1994:2-3)

Hierdie prosedure is aan bepaalde kriteria, norme of reels onderhewig en moet binne 'n bepaalde institusionele raamwerk funksioneer. Vrye en regverdige verkiesings is een van die noodsaaklike prosedures waarvolgens regeerders aan bewind kom en verteenwoordigers aanwys. Ander prosedures berus op die aanvaarding van fundamentele regte, wat die kwessie van 'n handves van menseregte in 'n demokrasie moontlik maak (Esterhuyse, 1994:1, 3-4).

Enkele onderskeidende kenmerke van 'n demokratiese bestel word kortliks aangedui om die bepalende invloed daarvan op politieke geletterdheid te illustreer.

In 'n demokrasie het elke burger van die land 'n gelyke bedingingsgeleentheid wat beteken dat hy indirek ' $n$ inspraak in die regering het. Hierdie staatstruktuur veronderstel dat meningsverskille deur debat en oorreding besleg sal word. Pickles (vgl. Brennan, 1981:105) stel dit dan ook so: "The strength of democracy must be built on ... readiness to arbitrate between conflicting truths by democratic methods, and to the satisfaction of the greatest number."

Om te kan deelneem aan die regering en om te kan debatteer oor verskille moet die burger kennis besit. Breman (1981:120) verduidelik dat in sy wydste betekenis die politieke teorie van 'n deelnemende demokrasie ook 'n opvoedkundige teorie is. Die rasionele kundigheid en betrokkenheid van die burger geniet dus prioriteit in 'n demokrasie omdat die demokrasie 'n kundige en betrokke burger veronderstel. Hierdie kundigheid bepaal die kwaliteit van die leiers en vorn 'n belangrike wyse van kontrole oor die staat (Trümpelmann, 1985:58; Ross, 1984:64). Dit is dus noodsaaklik dat geletterdheidsprogramme 'n integrale deel sal uitmaak van die skool se kurrikulum.

\section{Politieke geletterdheidsprogramme in Suid-Afrikaanse staatskole}

In lande soos Amerika, Brittanje en Wes-Duitsland word algemeen aanvaar dat die skool 'n verantwoordelikheid het on die kind ook op die gebied van die politiek te vonn met die oog op sy volwassewording in 'n demokrasie (Trümpelmann, 1986:11). Die vorming van die kind ten opsigte van die politiek was nog altyd 'n netelige onderwerp in die RSA. Olivier (1991:19) beskuldig die Christelik-nasionale onderwysfilosofie van die Nasionale Party gedurende 19481992 as ideologiese manipulasie. Volgens hom is skoolopvoeding deur die staat 
gemanipuleer om sekere leefpatrone te vestig en onderdanigheid aan die owerheid die norm te maak.

\subsection{Jeugweerbaarheid as skoolvak}

In 1972 is die Jeugweerbaarheidsprogram deur die Transvaalse Onderwysdepartement as 'n verpligte, nie-eksamenvak vir standerd ses tot tien ingestel. In die komponent Geestesweerbaarheid is temas soos burgerskap en menseverhoudinge betrek. Die doel hiervan was om 'n gelukkige, nuttige landsburger op te lei wat deur kennis van die land se probleme, geskiedenis en volkere sy land sal liefkry (Transvaalse Onderwysdepartement, 1987:5, 32). Joubert (1988:110) bevind dat komponente van politieke geletterdheid in dié program geakkommodeer word maar dat die onderwyser 'n deurslaggewende faktor by die onderrig daarvan is. Weens onvoldoende onderwysersopleiding vir die aanbieding van hierdie vak is daar by talle skole tuiswerk in hierdie periode gedoen (Struwig \& Trümpelmann, 1989:2). Die gevolg was dat politieke geletterdheid binne die program nie tot sy reg gekom het nie.

\subsection{Lewensopvoeding}

$\mathrm{Na}$ die verloop van 'n oriënteringsjaar is die Lewensopvoedingsprogram in 1994 deur die Transvaalse Onderwysdepartement in alle skole in Transvaal geïmplementeer om die Jeugweerbaarheidsprogram te vervang: "Lewensopvoeding is 'n gekoŏrdineerde, normgerigte opvoedingsprogram wat die leerling met lewenskennis, -vaardighede en -gesindhede toerus met die oog op die optimalisering van die kwaliteit van sy totale lewensituasie" (Transvaalse Onderwysdepartement, 1993:1-2). Hierdie doelstelling sluit onder andere die staatkundige as ervaringsterrein van die kind in. Hiermee word die ontwikkeling van staatkundige geletterdheid, die juridiese, die struktuur en funksies van die staat en politieke geletterdheid ingesluit. Die program konsentreer dus pertinent op begeleiding van die skolier tot politieke geletterdheid soos gedefinieer in hierdie artikel.

Die suksesvolle oordrag van politieke geletterdheid as deel van die inhoud van die Lewensopvoedingsprogram sal eers oor 'n paar jaar geëvalueer kan word.

\subsection{Politieke geletterdheid as deel van die Geskiedenis-kurrikulum}

Politieke geletterdheid is volgens Kapp (1992:4) 'n doelstelling van die vak Geskiedenis wat soos volg omskryf word:

Politieke kennis en insig moet stelselmatig by die leerling ontwikkel word om vir hom 'n politieke geletterdheid te verskaf, gebou op die bestudering van konkrete politieke ontwikkelinge soos dit hierdie gemeenskaps- en belangekringe raak. 
'n Ondersoek wat deur die Raad vir Geesteswetenskaplike Navorsing geloods is, het standerd sewe en nege leerlinge van skole in die RSA se beskouings ten opsigte van sekere stellings binne die vak Geskiedenis getoets en die volgende resultate is verkry:

- Die hoogste persentasie leerlinge wat die vak as bevorderlik vir die begrip van die huidige politieke situasie beskou, is swart leerlinge.

- Leerlinge uit die kleurling-, Indiër- en blanke bevolkingsgroepe het in hierdie volgorde met swart leerlinge saamgestem (Anon., 1992:45-60).

Politieke geletterdheid word tans deur middel van die vak Geskiedenis onderrig maar die bevindings van genoemde ondersoek (Anon.,1992:45-60) toon dat die gesindheid van sommige leerlinge ten opsigte van die vak nie positief is nie. Geskiedenis is ook 'n keusevak wat beteken dat nie alle leerlinge deur middel van dié vak polities-geletterd opgevoed word tot standerd tien nie.

\subsection{Politieke geletterdheid vir begaafdes}

Vir die hoogsbegaafde leerlinge van standerd vyf tot tien word 'n werkprogram, Staatkundig-wysgerige Studies, deur die Transvaalse Onderwysdepartement aangebied. In dié program word kennis ten opsigte van die ingewikkelde SuidAfrikaanse samelewing en begrippe soos demokrasie, stemreg, politieke partye en diktatuur oorgedra (Transvaalse Onderwysdepartement, 1986:1-13). Hierdie program betrek kennis en begrippe wat die leerling lei tot politieke geletterdheid, maar die getal leerlinge wat aan hierdie program deelneem, is baie beperk.

Akademici en opvoedkundiges is dit eens dat politieke geletterdheid binne die nuwe Suid-Afrikaanse regeringsbestel wat alle beginsels van demokrasie wil verreken, meer eksplisiet op skool onderrig moet word (Duvenhage, 1993; Universiteit Stellenbosch, 1993:1, 8-9). Ten spyte daarvan dat politieke geletterdheid reeds in die skoolkurrikulum ingesluit is, blyk die inhoud en die plek daarvan in die skoolkurrikulum nog steeds knelpunte te wees.

\section{Aanbevelings}

Die volgende aanbevelings word aan die hand gedoen om die burger politiesgeletterd binne 'n demokrasie in Suid-Afrika op te voed:

* Die instelling van 'n hoëvlakpos deur die onderwysowerhede vir die inisieer en bestuur van politieke geletterdheidsprogramme as opvoedingsaangeleentheid in alle skole in die Republiek van Suid-Afrika.

* Die onderrig van politieke geletterdheid as afsonderlike vak wat die volgende aspekte insluit: 
- $\quad$ Kennis van elke burger se regte (Handves van Menseregte), pligte en moontlike wyses waardeur hy by die politiek betrokke kan wees.

- $\quad$ 'n Kritiese kennis van die demokrasie in die RSA en demokrasieë van ander lande (veral dié in Afrika), asook relevante staatsfilosofieë en regeringstelsels.

- Kennis van die vervlegtheid van nasionale en internasionale politiek.

- Vaardighede en vermoëns wat tot intellektuele weerbaarheid by die burger sal lei sodat hy krities en denkend aan politieke prosesse kan deelneem. Hierdie denkvaardighede sal die burger toerus om alternatiewe te soek vir hedendaagse probleme. Hierby word kennis van die stemprosedure op plaaslike en nasionale vlak ingesluit.

* Alle aspirantonderwysers behoort opleiding te ontvang in politieke geletterdheid en die onderrig daarvan. Vir onderwysers wat reeds in die beroep staan, kan indiensopleidingskursusse aangebied word.

* Die massamedia kan gebruik word vir deurlopende politieke geletterdheidsprogramme.

* Onderwysprogramme gerig op volwasse leerders moet help om dié deelnemers polities geletterd te maak.

\section{Gevolgtrekking}

Politieke besluite en besluitnemingsprosesse beïnvloed byna elke faset van die mens se daaglikse lewe. Demokratiese prosesse vereis polities-geletterde burgers wat verantwoordelik hieraan kan deelneem. In die aanhef van die 1993Grondwet word die doel gestel van 'n gemeenskaplike Suid-Afrikaanse burgerskap vir ' $n$ soewereine en demokratiese regstaat, waarin daar gelykheid tussen alle mense is (RSA, Departement van Onderwys, 1994:23). Om hierdie doel te bereik sal politieke geletterdheid van elke burger vereis word. Die klimaat waarbinne politieke geletterdheid as 'n opvoedingsaangeleentheid kan geskied, is reeds geskep. Die daadwerklike onderrig daarvan moet spoedig as 'n prioriteit gestel word sodat 'n ware demokratiese kultuur gevestig kan word.

\section{Verwysings}

ANON. 1992. What our pupils think Yesierday and Todal', 24:45-60.

ANON 1995 Registration to be open Pretoria New's 3, Aug 18

ARISTOTLE. 1966 Politics. (Translated with introduction and notes by T A. Sinclair.) s. 1. : Penguin.

BEYERS, N. 1994. Land van goeie hoop De Kal 56-57, Junie 
BORNMAN, G.M. 1991. Die opvoeding van die volksleier: 'n histories-vergelykende en eksemplariese studie. Pretoria : Universiteit van Suid-Afrika. (M.Ed-verhandeling.)

BOYER, E.L. 1988 The building of a nation (AESAR) Freeman Butts Lecture - 1987 Educational Studies (American Educational Studies Association), 19:281-289.

BRENNAN, T. 1981. Political education and democracy. Cambridge : Cambridge University Press.

BROWNHILL, R. \& SMART, P. 1989. Political education. London : Routledge.

DE VRIES, C.G. 1995. Betrek leerlinge by bestuur-SAOU. Beeld: 5, Julie 6.

DE KLERK, W.J., DUVENAGE, B \& VAN WYK, J.H. 1973. Roeping en werklikheid. Handboek vir Interfakultêre Wysbegeerte. Potchefstroom : Potchefstroom Herald.

DU PLOOY, J.L., GRIESEL, G.J. \& OBERHOLZER, M.O. 1985. Fundamentele Pedagogiek vir gevorderde studente. Pretoria : HAUM.

DUVENHAGE, A. 1993. Korrespondensie. Universiteit van die Oranje-Vrystaat, Departement Politieke Wetenskap, 1 November, Bloemfontein.

ESTERHUYSE, W. 1994. Wat is demokrasie? Tydskrif vir Geesteswetenskappe, 34(1) 1-2, Maart.

FARNEN, R E. 1990. Integrating political science, education and public policy: International perspectives on decision-making, systems theory and socialization research. International Studies in political socialisation and political education (4). Frankfurt am Main : Lang.

JOUBERT, J.P 1988 'n Fundamentele pedagogiese evaluering van die plek en waarde van politieke geletterdheid in die jeugweerbaarheidsprogram. Pretoria : Universiteit van Pretoria (M.Ed-verhandeling.)

KAPP, P H. 1992. Doelstellings, doelwitte en kriteria. Gister en Vandag, 24:3-10.

KOTZE, H.J. \& VAN WYK, J.J. 1980. Basiese konsepte in die politiek. Johannesburg McGraw-Hill.

KRIEGER, J 1993. The Oxford companion to politics of the world New York: Oxford University

LANDMAN, W.A 1993 Opvoedkunde en sy verhouding tot ander wetenskappe (Politieke wetenskap en natuurwetenskap). B.Ed-aantekeninge. Instituut vir Opvoedkundige Navorsing. Universiteit van Suid-Afrika, Pretoria.

LISTER, I. 1976. The aims and methods of political education in schools. Teaching Politics, $1(18): 1-18$

ODENDAL, F.F. red, SCHOONEES, P C., SWANEPOEL, C.J., DU TOIT, S.J \& BOOYSEN, C M. 1994. HAT. Verklarende Handwoordeboek van die Afrikaanse taal 3de hersiene, uitgebreide uitgawe. Midrand : Perskor

OLIVIER, F. 1991. Om by móre te kom, moet jy gister los. Vrye Weekblad. 19, Maart 15

PRETORIUS, F.J. 1985 Ideologie en opvoeding: 'n metabletiese oopdekking. Pretoria : Universiteit van Suid-Afrika. (M.Ed-verhandeling.)

ROSS, K 1984 We pay a high price for the failure of our political education. The Chronicle of Higher Education, 28(6):64

RSA DEPARTEMENT VAN ONDERWYS. 1994 Onderwys en opleiding in 'n demokratiese Suid-Afrika. Pretoria : Staatsdrukker

SAUK. 1995. TV 1-Nuus, 8 Augustus

SPIRO, H.J 1970. Politics as the master science: From Plato to Mao. New York : Harper \& Row.

STRUWIG, F \& TRUMPELMANN, MH 1989. Geestesweerbaarheid en politieke geletterdheid feit of mite? Gister en Vandag, 18:2-6 
THE PRETORIA NEWS

Kyk

ANON 1995.

TRANSVAALSE ONDERWYSDEPARTEMENT. 1986 Werkprogram vir hoogsbegaafde leerlinge. Staatkundige wysgerige studieprogramme $5,6,7,8,9,10$. Pretoria Staatsdrukker

TRANSVAALSE ONDERWYSDEPARTEMENT. 1987. Die geestesweerbaarheidsprogram in die sekondere skool. Pretoria : Staatsdrukker

TRANSVAALSE ONDERWYSDEPARTEMENT 1993. Die lewensopvoedingsprogram Die fundering van die kern-onderrigprogramme. Pretoria : Staatsdrukker

TRUMPELMANN, M.H. 1985. Politieke geletterdheid as verantwoordelikheid van die sekondêre skool Johannesburg : Randse Afrikaanse Universiteit. (D.Ed-proefskrif.)

TRUMPELMANN, M.H. 1986. Politiek op skool: burgers in 'n demokrasie moet leer dink Beeld. 11, Augustus 10.

UNIVERSITEIT VAN STELLENBOSCH. 1993. Handleiding vir studente in politieke wetenskap. Departement Politieke Wetenskap : Stellenbosch 